\title{
Editorial:
}

\section{Segregación Escolar y Meritocracia}

\section{School Segregation and Meritocracy}

\author{
Cynthia Duk *1 \\ F. Javier Murillo 2 \\ ${ }^{1}$ Universidad Central de Chile, Chile \\ ${ }^{2}$ Universidad Autónoma de Madrid, España
}

La segregación escolar es un problema complejo de naturaleza multifactorial, cuyas causas están asociadas a factores exógenos al sistema educativo, como la segregación residencial o territorial que es reflejo de los altos niveles de segmentación social que afectan a la gran mayoría de los países de la región. Pero también tiene que ver con factores asociados al diseño de políticas educativas sustentadas en modelos de cuasi-mercado, que han fomentado la privatización de la educación, la competencia entre escuelas por resultados de aprendizaje y la libre elección, favoreciendo incluso mecanismos selectivos de acceso según criterios socioeconómicos, de rendimiento académico y procedencia étnico-cultural. Todas ellas políticas que, sin duda, han contribuido a generar una alta segregación (Murillo, Duk, Martínez-Garrido, 2018).

Entre los factores aducidos, uno de los aspectos poco analizado es el papel de la selección sobre la segregación escolar. Desde la perspectiva del derecho a la educación y la inclusión, las prácticas de selección son un tipo de discriminación que no solo limitan las oportunidades de los estudiantes, afectan su dignidad y el derecho de las familias a elegir la educación que quieren para sus hijos e hijas, sino que generan segmentación en los sistemas educativos. Avanzar hacia sistemas de acceso igualitario debiera ser una prioridad de política pública y una de las primeras medidas de dicha política, erradicar toda forma de selección arbitraria que atente contra el derecho a la educación y la igualdad de oportunidades.

En contextos con altos niveles de injusticia distributiva, abordar este problema supone enfrentar a lo menos dos grandes dificultades que lo hacen altamente complejo. Por un lado, la existencia de importantes niveles de asimetría en cuanto a calidad de la oferta educativa, que conlleva a que las escuelas con mejores resultados y reputación sean sobredemandadas, concentrando la población escolar con mayor capital socioeconómico y cultural. Por otro lado, la existencia de posturas y presiones contrapuestas al principio de acceso igualitario, sustentadas en la defensa de la meritocracia como valor que hace justicia al mérito y esfuerzo personal. La conjunción de estos dos factores, escasa oferta de calidad concentrada en ciertas escuelas y mérito académico como criterio para acceder a las mejores oportunidades, conforman un escenario poco promisorio para reducir la segregación escolar, a no ser que, de una vez por todas, se tomen medidas serias al respecto.

*Contacto:cduk@ucentral.cl

ISSN: 0718-7378

www.rinace.net/rlei/ 
Una de las medidas que puede ayudar a mitigar la desigualdad en el acceso, es disponer de sistemas únicos de admisión debidamente regulados, que garanticen la transparencia de los procesos de postulación, combinados con medidas de acción afirmativas para aquellos estudiantes en situación de mayor desventaja. Este tipo de decisiones puede ser una buena opción para sistemas educativos con una larga tradición de libre elección como por ejemplo el caso de Chile. La legislación chilena reconoce dos principios que suelen entrar en conflicto o colisión, según el prisma con que se interpreten, el derecho de los padres a elegir la educación que deseen para sus hijos/as y el derecho a la libertad de enseñanza. Este último, ha sido un argumento extensamente utilizado por los centros educativos para elegir a las familias y estudiantes que se "ajusten" o "compartan" el proyecto educativo de la escuela, haciendo uso de procedimientos de selección bastante sofisticados (pruebas de ingreso, sesiones de juego o de observación, entrevistas a los padres, antecedentes escolares, socioeconómicos, religiosos...).

En este sentido, el caso chileno resulta interesante de comentar. Primero, por ser uno de los países de la región que ocupa los primeros lugares en cuanto a los niveles de desigualdad social y educativa que exhibe. Los datos hablan por sí solos, el 1\% de la población controla el 33\% de la riqueza del país, lo que encuentra su correlato en educación, donde la distribución de las oportunidades educativas es altamente desigual e injusta, siendo la segregación escolar por origen socioeconómico y cultural, como por rendimiento académico, uno de los problemas más serios que el país enfrenta. Segundo, porque el 2015 inició una reforma educacional de gran calado, con la finalidad de corregir aquellos elementos estructurales del sistema que favorecen la segregación escolar, entre otros aspectos. Así, mediante la Ley de Inclusión Escolar se pone termino de manera gradual a dos importantes barreras de entrada a las escuelas que reciben financiamiento del estado (92\% de la oferta), la selección de los estudiantes por parte de las escuelas y el copago por parte de las familias (cuotas que pagan las familias en escuelas privadas subsidiadas por el estado).

Para tal efecto, se crea un sistema de admisión escolar (SAE) que responde al principio de justicia al tratar a todos los postulantes por igual. Un sistema centralizado donde todos las escuelas públicas o subvencionadas están sujetas a las mismas reglas. El SAE asigna a estudiantes a su mayor preferencia siendo todas las escuelas obligadas a aceptar a cualquier postulante que los elija. De esta forma, a ninguna familia se le asigna un centro que no haya elegido, excepto que no haya cupos en ninguna de sus preferencias ( $0,3 \%$ de los casos en proceso 2017, 4 de los casos en proceso 2018). Cuando hay colegios con sobredemanda (en 2018 alrededor del $27 \%$ no queda en alguna de sus preferencias), el sistema asigna la escuela priorizando con base a cuatro criterios (Carrasco y Honey, 2019, p. 9). En último término, la escasez de cupos se resuelve al azar otorgando a todos los postulantes restantes la misma probabilidad de obtener un cupo.

Los datos aportados por el SAE a partir de sus dos primeros años de implementación (2017 y 2018), es de enorme valor para informar al sistema, respecto no solo de la relación entre la oferta demanda, la capacidad ociosa del sistema, sino también sobre cómo se comportan las preferencias de las familias, sus expectativas, información de gran utilidad para una mejor comprensión acerca del fenómeno de la segregación escolar y alimentar las políticas públicas para abordarla de manera más efectiva.

A este respecto, el estudio realizado por Carrasco y Honey (2019) da cuenta de la existencia de diferencias en las postulaciones que realizan las familias de mayores recursos 
respecto de aquellas de menores niveles socioeconómicos. En el primer caso, prefieren aquellas escuelas de mejor desempeño académico, es decir que obtienen resultados sobre el promedio en matemáticas y lectura, siendo a su vez las más deseadas y con mayor sobredemanda. En cambio, las familias de condiciones vulnerables tienden a elegir escuelas de menor desempeño o terminan eligiendo lo que hay, en vista de la desigualdad de la oferta. El estudio muestra, además, algo similar respecto de las preferencias de las familias en función del rendimiento previo de sus hijos/as. Las familias de estudiantes con alto nivel de rendimiento académico postulan en mayor proporción a colegios de desempeño alto, con resultados sobre el promedio, que las familias de los estudiantes que tienen un bajo nivel de rendimiento. No sería aventurado pensar que la consistencia observada entre altas expectativas y orientación al logro de los padres expliquen en parte el mejor desempeño que alcanzan sus hijos. Un tercer hallazgo digno de mencionar, es que las postulaciones de las familias con hijos de nivel insuficiente, muestran una discreta inclinación a postular a colegios de alto desempeño o previamente selectivos, lo que podría ser una señal de aspiraciones antes no expresadas y de cómo un sistema de elección puede limitar o ampliar las oportunidades educativas de los estudiantes.

No deja inquietarnos que a dos años de la creación SAE y sin que aún haya entrado completamente en régimen haya sectores que buscan reponer las prácticas de selección según méritos académicos, en aquellos centros educativos de alto desempeño y calidad, que son los más atractivos y sobre demandados por las familias.

Muy por el contrario, la promesa de una educación inclusiva lo que busca es reducir las desigualdades y, por tanto, la segregación escolar ya sea por desempeño académico, por procedencia cultural o nivel socioeconómico, es su peor enemigo. Por lo mismo, para avanzar en la dirección deseada no hay argumento que se pueda sostener en una "supuesta justicia" basada en la meritocracia, que pretende asegurar que la reducida oferta de calidad de que dispone el país, concentre a aquellos estudiantes de mejor rendimiento académico, y por la misma vía de selectividad, asegurar que dichos centros educativos se diferencien y mantengan sus altos niveles de desempeño escolar.

Cuánto tiempo más tendrá que pasar para que comprendamos que no hay atajos, que el único camino posible para avanzar hacia una educación inclusiva, equitativa y de calidad para todos -compromiso asumido por nuestros países en el marco de la Agenda 2030 de Desarrollo Sostenible-, es poniendo todos los esfuerzos y recursos para fortalecer una educación pública de calidad, asegurando igualdad de condiciones para que los estudiantes de sectores más desfavorecidos y/o de menor desempeño tengan acceso a iguales oportunidades en cuanto a calidad.

La pregunta de fondo es si como sociedad queremos educación de calidad para todos o solo para que algunos sigan manteniendo sus privilegios

\section{Referencias}

Carrasco, A. y Honey, C. (2019). Nuevo sistema de admisión escolar y su capacidad de atenuar la desigualdad de acceso a colegios de calidad: al inicio de un largo camino. Santiago de Chile: Centro Justicia Educacional - Universidad Católica de Chile.

Murillo, F. J., Duk, C. y Martínez-Garrido, C. (2018) Evolución de la segregación socioeconómica de las escuelas de América Latina. Estudios Pedagógicos, 44(1), 157-179.

https://doi.org/10.4067/S0718-07052018000100157 